\title{
INDUCTION OF SPOROPHYTIC DIVISION IN ORCHIDS MICROSPORES BY STRESS
}

\author{
Ari Indrianto ${ }^{1}$, Chairani Siregar ${ }^{2}$, Sutikno Linuhung ${ }^{3}$, Mekartinita ${ }^{1}$, Tri Sartikoningsih ${ }^{1}$ \\ ${ }^{1}$ Faculty of Biology UGM Yogyakarta \\ ${ }^{2}$ Faculty of Agriculture UNTAN Pontianak - Kalimantan Barat \\ ${ }^{3}$ ROYAL Orchid Nursery - Lawang - Jawa Timur
}

\begin{abstract}
Orchid is one of the important ornamental plants in Indonesia this plant generally propagated by seed. Enhancing quality of this plant through breeding technology by various plant tissue culture methods and biotechnology, including doubled haploid technology are necessary. The most efficient method in creating doubled haploids plant is via microspore embryogenesis. We have develop new, innovative doubled haploid technology using the technique of isolated microspore culture. The goals are to obtain data on the male gametophyte development, viable embryogenic microspores, microspores derived embryos and double haploid plants of Orchid.

Development of male gametophytes were analysed by isolation of microspores and pollen at various stages and staining with DAPI. Isolated orchid buds of Dendrobium hybrid 1, Vanda tricolor and Spathoglotis plicata were subjected to cold temperatures $\left(4^{\circ} \mathrm{C}\right)$ for 7 days, microspores were then isolated by crushing the pollinia using glass rod and cultured them in embryogenesis A2, NP, MS and VW medium, viability of the microspores were determine by using Flourescein diacetate (FDA). Isolated Orchid pollinia were cultured in starvation medium $B$ at various temperatures and duration of time to evaluate embryogenic response, isolated microspores then were cultured further in the basic embryogenesis medium and incubated at $25^{\circ} \mathrm{C}$ in the darkness.

The result showed that floral characteristics for the late-uninucleate stage of the microspores were different for every orchid spesies. Ovulum lenght was used for Vanda, while in Dendrobium, Phalaenopsis, Arachnis, Spathoglottis plicata and Cattleya, varied length of flower bud was used. Isolated microspores of Dendrobium hybrid 1, Vanda tricolor and Spathoglotis plicata at $7^{\text {th }}$ days of culture in different media formulation showing different respond of viability. Medium A2 keeping viability of Dendrobium hybrid 1 microspores better than any other medium, while in Vanda tricolor and Spathoglotis plicata embryogenesis NP medium was superior. Incubation of orchid pollinia at 4 and $25^{\circ} \mathrm{C}$ were successfully maintain viability of the microspores during starvation periods but not able to block gametophytic development. In contrast starved pollinia at $33^{\circ} \mathrm{C}$ were succesfully block gametophytic development, percentage of embryogenic microspores after starvation of isolated pollinia at $33^{\circ} \mathrm{C}$ for 4 days was superior compare to any other treatments. Symmetrical divisions and some multicellular structures were observed, which were clear indication for the sporophytic development of microspore-derived embryos, they had developed and after a few weeks they degenerated and died.
\end{abstract}

Keywords: flower bud-pollinia-microspore-stress-embriogenic-embryo-Orchid

\section{INTRODUCTION}

Orchid is one of the important ornamental plants in Indonesia this plant generally propagated by seed. Enhancing quality of this plant through breeding technology by various plant tissue culture methods and biotechnology, including doubled haploid technology are necessary.

The genetic diversity is inherited from generation to generation through pollen and ovule (male and female gamete cells). The nucleus of male gamete cell encountering and fused with the nucleus of egg cell resulted in zygote, then develop into a plant and in turn allowing a genetic inheritance in a continuous manner. Direct plant regeneration via microspore embryogenesis, and doubling of its chromosomes number, is more efficient in expressing

ISSN 2413-0877 @ 2015 The Authors.

Published by KnowledgeE Publishing Services This is an open access article under the CC BY-NC-ND license (http://creativecommons.org/licenses/by-nc-nd/4.0)

Selection and Peer-review under responsibility of the 3rd ICBS-2013

http://dx.doi.org/10.18502/kls.v2i1.181 
genetic diversity brought by haploid microspores because plant phenotype was not covered by the dominant effect (Morrison \& Evans, 1988).

Quality improvement of orchid can be achieved by creating new hybrid, because of heterosis phenomena. The important tools that facilitate the production of $F 1$ hybrids is a rapid way of producing homozygouse parent lines, complete homozygozity of parent lines ensures uniformity of the hybrid plants. Currently, the best way of making homozygous parent lines is through the regeneration of plants from haploid microspores or pollen, in which chromosome number is doubled (Touraev et al.,1996a).

The potential of immature pollen to deviate from its normal developmental pathway, giving rise to haploid plants via embryogenesis, is known since the original experiments of Guha and Maheshwari $(1964,1966)$ who observed the formation of embryos of pollen origin in anther cultures of Datura innoxia.

The initial switch from pollen development to embryogenic development is the main key to success in the generation of doubled haploid plants. Application of stress is an important factor controlling this switch in the developmental fate. Different stress conditions are effective in inducing the switch between the gametophytic and sporophytic generations in homosporus plants; similarly, microspore of flowering plants can be switched toward sporophytic development by a variety of shock treatments (Bell, 1992; Dickinson, 1994). Sucrose starvation, in particular, appears to be the major signal controlling the developmental fate of tobacco microspores, as it is the most effective treatment for embryogenic induction from different developmental stages, uninucleate microspores as well as mid-bicellular pollen. Starvation may also be a general trigger of pollen embryogenesis in higher plants, as it is effective not only in tobacco but also in other species such as barley (Hoekstra et al., 1992), wheat (Indrianto et al, 1999); rice (Ogawa et al, 1994).

Objective of this research is to develop new, innovative doubled haploid technology for Orchid using the technique of isolated microspore culture. The goals are to obtain data on the male gametophyte development, embryogenic microspores, microspores derived embryos of Orchid.

\section{MATERIALS AND METHODS}

\section{Determination of Late-uninucleate microspore stage}

Development of male gametophytes were analysed by isolation of microspores and pollen at various stages and staining with DAPI, to determine state of the nuclei. Data obtained were used to characterize developmental stages of male gametophyte of Orchid and identification of correlation between stage of male gametophyte and bud size, morphology or other simple markers.

\section{Temperature stress on isolated Orchid buds}

Cold shock pretreatments of buds were shown to be very effective to maintain viability of the microspores and to block gametophytic pathway and induce embryogenesis. Isolated orchid buds at different developmental stages were subjected to cold temperatures $\left(4^{\circ} \mathrm{C}\right)$ for 7 days, microspores were then isolated by crushing the pollinia using glass rod and cultured them in embryogenesis A2, NP, MS and VW medium. 


\section{Starvation of isolated Orchid pollinia}

Isolated Orchid pollinia at different stages of development were subjected to starvation in carbohydrate and nitrogen-free medium B, which was shown to trigger the formation of embryogenic microspores in the number of species, including tobacco (Touraev et al, 1996a), wheat (Indrianto, et al, 2001) and rice (Ogawa et al, 1994). Pollinia were cultured in medium $B$ at various temperatures and duration of time to evaluate embryogenic response and simultaneously the block of gametophytic pathway, the microspores allowed to shed and isolated microspores were cultured further in the basic embryogenesis medium and incubated at $25^{\circ} \mathrm{C}$ in the darkness.

\section{Regeneration of Orchid microspore-derived embryos.}

It was shown that regeneration frequency is absolutely dependent on the quality of the embryos. Therefore, success of regeneration will be dependent on the optimization of culture conditions for initiation and further development of an embryo. Well developed Orchid microspore-derived embryo were then transferred to basic regeneration medium with a low concentration of carbohydrates on solid medium and incubated under light condition.

\section{RESULTS AND DISCUSSION}

\section{Determination of Late-uninucleate microspore stage}

Staging is a basic step to initiate microspore culture, since it allows to corelate the most suitable microspore stage for androgenesis induction with a flower bud trait measurement in each orchid species. The main objective is to obtain data on the male gametophyte development of orchids. Specific objective is the description of male development in relation to morphological characteristics of buds of various developmental stages. DAPI (Diamidinophenyl-indole) is used to establish the state of microspore nucleus/nuclei at a given flower bud developmental stage ultimately allowing to find out the reaction of each microspore stage to the induction of androgenic haploidy through isolated microspore culture techniques.

Table 1. Floral characteristics for the Late-uninucleate stage of the microspores

\begin{tabular}{llc}
\hline \multicolumn{1}{c}{ Species } & $\begin{array}{c}\text { Morphological } \\
\text { characteristic }\end{array}$ & Range (mm) \\
\hline Dendrobium secundum & Flower bud length & $11-14$ \\
Dendrobium hybrid I & Flower bud length & $14-16$ \\
Dendrobium hybrid II & Flower bud length & $13-15$ \\
Oncidium sweet sugar & Flower bud length & $8.4-9.8$ \\
Spathoglottis plicata & Flower bud length & $7-9$ \\
Vanda tricolor & Ovulum length & $10-15$ \\
Vanda limbata & Flower bud length & $5-8$ \\
Arachnis Megy Oei & Flower bud length & $8-10$ \\
Cattleya & Flower bud length & $36.3-38.2$ \\
Phalaenopsis amabilis & Flower bud length & $10-12$ \\
Phalaenopsis belina & Flower bud length & $10-12$ \\
\hline
\end{tabular}

A good correlation between the floral trait and the developmental stage was observed in Orchid. Table 1 shows the measurement range of Orchid flower buds corresponding to the late-uninucleate microspore stage (from young microspore to vacuolated microspore). Floral 
characteristics for the late-uninucleate stage of the microspores are different for every orchid spesies. In Vanda, ovulum length is used for determining morphological characteristic of flower bud containing late-uninucleate microspores, while in Dendrobium, Phalaenopsis, Arachnis, Spathoglottis plicata and Cattleya, flower bud length is used.

Vacuole of the late-uninucleate microspores are not clearly seen, DAPI stained of these microspores showed that position of the nucleus was in the periphery close to the microspore wall. Microspores gametophytically programmed to differentiate into mature pollen, the first nuclear mitosis division is asymmetric result in small generative cell inside the cytoplasm of vegetative cell, in this binucleate pollen both vegetative and generative nucleus have different fate of development, vegetative nucleus is not develop further (remain in G1 of the cell cycle) while generative nucleus will divide symmetrically to produce sperm cells (McCormic, 1993). The most responsive stage of pollen development to induce embryogenesis is late-uninucleate to pre-mitosis. Table 1 showed that the flower bud length for Dendrobium containing microspores at the late-uninucleate is ranging between 11 to $16 \mathrm{~mm}$.

\section{Temperature stress on isolated Orchid buds}

Cold shock pretreatments of buds were shown to be very effective to maintain viability of the microspores. Viability of the microspore means that it have not plasmolysed, the cytoplasm still intact and able to grow, germinate or develop. Isolated orchid buds at different developmental stages were subjected to cold temperatures $\left(4^{\circ} \mathrm{C}\right)$ for 7 days, microspore were then isolated by crushing pollinia using glass rod and cultured in embryogenesis medium. Maintenace of the viability of isolated microspores during the first days of in vitro culture is absolutely essential for microspore embryogenesis. To find optimal media formulations for maintaining the viability of isolated Orchid microspores, some basic medium formulation of orchid were tested namely NP, MS, VW and A2.

According to Duncan and Heberle, (1976) cold pre-treatment slows down degradation processes in the anther tissues thus protecting microspores from toxic compounds released in the decaying anthers. Therefore Cold shock pretreatments of buds were shown to be very effective to maintain viability of the microspores. According to Dafni and Firmage (2000) viability of the microspore means that it had the capacity to live, grow, germinate or develop. Maintenance of the viability of isolated microspores during the first days of in vitro culture is absolutely essential for microspore embryogenesis. Isolated microspores of Dendrobium hybrid 1, Vanda tricolor and Spathoglotis plicata at $7^{\text {th }}$ days of culture in different media formulation showing different respond of viability. Viability of the microspores were determine by using Flourescein diacetate (FDA), this test have two aspects of viability that were reaction of esterase activity present in the cytoplasm and an intactness of cell membrane. Table 2 showed that embryogenesis medium A2 keeping viability of Dendrobium hybrid 1 microspores better than any other medium, while in Vanda tricolor and Spathoglotis plicata embryogenesis NP medium was superior. Experiments by using fresh flower bud, without any cold pretreatment, was not able to maintain viability of isolated microspores more than 4 days, almost all isolated microspores plasmolysed and finally die (data not shown). 
Table 2. Percentage of viable isolated microspores of Dendrobium hybrid 1, Vanda tricolor and Spathoglotis plicata at $7^{\text {th }}$ days of culture in different media formulation, percentage is counted from at least 300 microspores per culture dish.

\begin{tabular}{lcccc}
\hline \multirow{2}{*}{ Orchid } & \multicolumn{4}{c}{ Embryogenesis Media } \\
\cline { 2 - 5 } & NP & MS & VW & A2 \\
\hline Dendrobium hybrid 1 & $17.55 \pm 1.77$ & $21.22 \pm 3.92$ & $10.98 \pm 2.31$ & $22.62 \pm 2.12$ \\
\hline Vanda tricolor & $25.48 \pm 1.45$ & $16.83 \pm 1.58$ & $13.49 \pm 1.43$ & $22.19 \pm 1.68$ \\
\hline Spathoglottis plicata & $26.46 \pm 0.99$ & $16.2 \pm 1.29$ & $13.32 \pm 1.6$ & $22.76 \pm 0.83$ \\
\hline
\end{tabular}

\section{Starvation of isolated Orchid pollinia}

Isolated Orchid pollinia of Dendrobium hybrid 1, Vanda tricolorand Spathoglottis plicata were subjected to starvation in carbohydrate and nitrogen-free medium $B$, which was shown to trigger the formation of embryogenic microspores in wheat and tobacco (Indrianto, et al, 1999; Touraev et al, 1997). Pollinia were cultured in starvation medium B and incubated at various temperatures and duration of time to evaluate embryogenic response and simultaneously the block of gametophytic pathway. The microspores allowed shedding and isolated microspores were cultured further in the basic embryogenesis A2 medium and incubated at $25^{\circ} \mathrm{C}$ in the darkness. Incubation of orchid pollinia at 4 and $25^{\circ} \mathrm{C}$ were successfully maintain viability of the microspores during starvation periods but not able to block gametophytic development as indicated by germinating pollen. In contrast starved pollinia of Dendrobium hybrid 1, Vanda tricolor and Spathoglottis plicata at $33^{\circ} \mathrm{C}$ were succesfully block gametophytic development, pollinia spontaneously shed their embryogenic microspores.

Table 3. Percentage of embryogenic microspores after starvation of isolated pollinia at different temperature incubation

\begin{tabular}{|c|c|c|c|}
\hline \multirow[b]{2}{*}{ Temperature } & \multicolumn{3}{|c|}{ Starvation period } \\
\hline & 2 days & 4 days & 6 days \\
\hline \multicolumn{4}{|c|}{ Spathoglottis plicata } \\
\hline $4{ }^{\circ} \mathrm{C}$ & - & - & - \\
\hline $25^{\circ} \mathrm{C}$ & $1.28 \pm 0.5$ & $0.82 \pm 0.18$ & $0.57 \pm 0.23$ \\
\hline $33^{\circ} \mathrm{C}$ & $2.47 \pm 0.47$ & $5.18 \pm 0.75$ & $0.89 \pm 0.72$ \\
\hline \multicolumn{4}{|l|}{ Vanda tricolor } \\
\hline $4{ }^{\circ} \mathrm{C}$ & - & - & - \\
\hline $25^{\circ} \mathrm{C}$ & $5.39 \pm 0.53$ & $3.56 \pm 0.7$ & $1.57 \pm 0.49$ \\
\hline $33^{\circ} \mathrm{C}$ & $13.86 \pm 1.25$ & $21.25 \pm 1.62$ & $8.15 \pm 1.28$ \\
\hline \multicolumn{4}{|c|}{ Dendrobium hybrid1 } \\
\hline $4{ }^{\circ} \mathrm{C}$ & - & - & - \\
\hline $25^{\circ} \mathrm{C}$ & $20.05 \pm 1.64$ & $10.03 \pm 1.17$ & $6.7 \pm 1.52$ \\
\hline $33^{\circ} \mathrm{C}$ & $15.23 \pm 2.89$ & $49.16 \pm 0.89$ & $27.72 \pm 0.63$ \\
\hline
\end{tabular}

Population of shed microspores contain big enlarge embryogenic microspores and small plasmolysed microspores. Enlarge microspore have thinner wall layer compare to normal gametophytic microspores. Cytoplasm of enlarged microspores, from pollinia pretreated at $33^{\circ} \mathrm{C}$ were clear without starch grains indicate that amylogenesis which is normally occur in normal gametophytic development of the microspores as reserve materials, had blocked during temperature stress of the pollinia. The nucleus of big enlarge embryogenic microspores 
have condenced chromatin, some nucleus of embryogenic microspores had divide symmetrically (Figure 1).

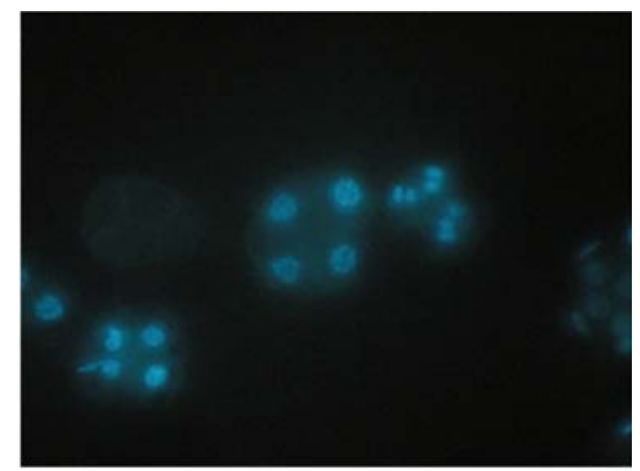

Figure 1. Embryogenic microspores of Dendrobium hybrid 1 after starvation of isolated pollinia at $33^{\circ} \mathrm{C}$ for 4 days.

Symmetrical division of embryogenic microspores was the indication of blocking normal gametophytic development of the microspores, leading to formation of multicellular structure (proembryo). Table 3 showed that percentage of embryogenic microspores of Dendrobium hybrid 1, Vanda tricolor and Spathoglottis plicata after starvation of isolated pollinia at $33^{\circ} \mathrm{C}$ for 4 days was superior compare to any other treatments

\section{Regeneration of Orchid microspore-derived embryos}

Orchid pollinia isolated from flower buds of Dendrobium hybrid 1 and Spathoglottis plicata were cultured in starvation medium $\mathrm{B}$ and incubated at $33^{\circ} \mathrm{C}$ for 4 days. Microspores then were isolated and cultured in embryogenesis medium A2 incubated at $25^{\circ} \mathrm{C}$ in the darkness. In the first week of culture isolated microspores were able to keeping their viability in embryogenesis A2 medium. Symmetrical divisions and some multicellular structures were observed (Figure 2), which are clear indication for the sporophytic development of microspore-derived embryos, they had developed and after a few weeks they degenerated and died.
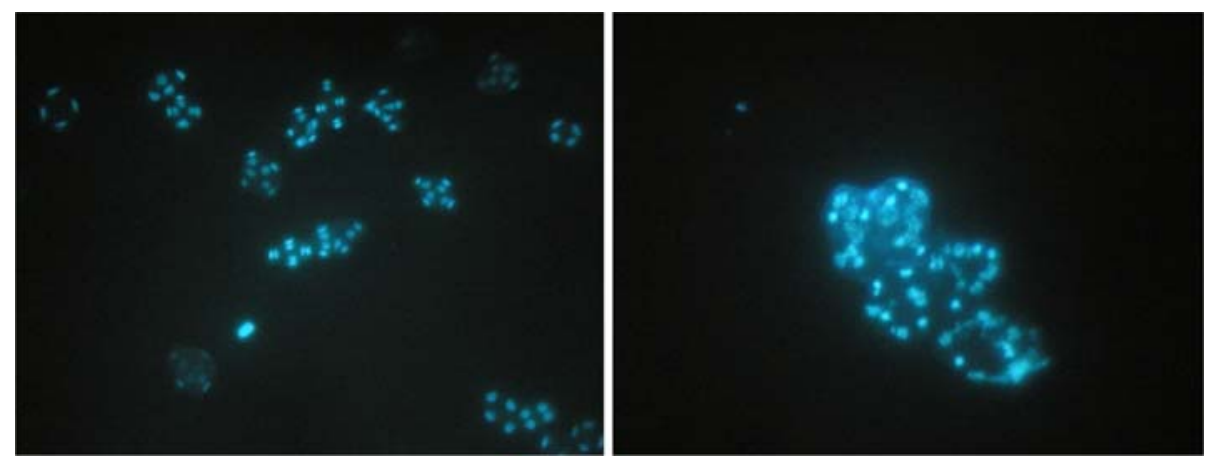

Figure 2. Symmetrical divisions and multicellular structures of embryogenic microspores of Dendrobium hybrid 1 in embryogenesis medium A2 


\section{ACKNOWLEDGEMENT}

The research was conducted as the realization of the implementing contract of Indonesia-Managing Higher Education for Relevance and Efficiency (I-MHERE) Project Research Grant Letter of Agreement Number: UGM/BI/1308///05/04 on June $3^{\text {rd }}, 2011$.

\section{REFERENCES}

Bell, P.R.1992. Apospory and apogamy: Implications for understanding the plant life cycle. Int J Plant Sci 153: 123-136.

Binarova, P., G. Hause, V. Cenklova, J.H.G. Cordewener, and M.M. Van Lookeren Campagne. 1997. A short-severe heat shock is required to induce embryogenesis in late bicellular pollen of Brassica napus L. Sex. Plant Reprod 10:200-208

Cordewener, J.H.G., R. Busink, J.A. Traas, J.B.M Custers, H.J.M. Dons, and M.M. Van Lookeren Campagne. 1994. Induction of microspore embryogenesis in Brassica napus L. is accompanied by specific changes in protein synthesis. Planta 195:50-56

Cordewener, J.H.G., G. Hause, E. Görgen, R. Busink, B. Hause, J.J.M. Dons, A.A.M. Van Lammeren, M.M. Van Lookeren Campagne, and P. Pechan. 1995. Changes in synthesis and localization of the $70 \mathrm{kDa}$ class of heat shock proteins accompany the induction of embryogenesis in Brassica napus L microspores. Planta 196:747-755

Dafni, A., and D. Firmage. 2000.Pollen viability and longevity: Practical, ecological and evolutionary implications. Plant Syst.Evol.222: 113-132

Dickinson, H.G. 1994. The regulation of alternation of generation in flowering plants. Biol Rev 69:419-442

Duncan, E.J., and E. Heberle. 1976. Effect of temperature shock on nuclear phenomena in microspores of Nicotiana tabacum and consequently on plantlet production. Protoplasma 90:173-177

Garrido, D., O. Vicente, E. Heberle-Bors, and M. Isabel Rodriguez-Garcia. 1995. Cellular changes during the acquisition of embryogenic potential in isolated pollen grains of Nicotiana tabacum. Protoplasma 186:220-230.

Guha, S., and S.C. Maheshwari. 1964. In vitro production of embryos from anther of Datura. Nature 204: 497.

Guha, S., and S.C. Maheshwari. 1966. Cell division and differentiation of embryos in the pollen grains of Datura in vitro. Nature 212: 97-98.

Hause, B., G. Hause, G. Pechan, and A.A.M. Van Lammeren. 1993. Cytoskeletal changes and induction of embryogenesis in microspore and pollen cultures of Brassica napus $L$. Cell Biol Int 17:153-168

Hoekstra, S., M.H. van Zijderveld, J.D. Louwerse, F. Heidekamp, and F. van der Mark. 1992. Anther and microspore culture of Hordeum vulgare L. cv. Igri. Plant Sci 86: 89-96.

Indrianto, A., E. Heberle-Bors, and A. Touraev. 1999. Assessment of various stresses and carbohydrates for their effect on the induction of embryogenesis in isolated wheat microspores. Plant Sci 143: 71-79.

Indrianto, A., I. Barinova, A. Touraev, and E. Heberle-Bors. 2001. Tracking individual wheat microspores in vitro: Identification of embryogenic microspores and body axis formation in the embryo. Planta 212: 163-174 
Kyo, M., and H. Harada. 1990a. Specific phosphoproteins in the initial period of tobacco pollen embryogenesis. Planta $182: 58-63$.

Yo, M., and H. Harada. 1990b. Phosphorylation of proteins associated with embryogenic dedifferentiation of immature pollen grains of Nicotiana rustica. J. Plant Phsiol 136:716722

Mc Cormick, S. 1993. Male gametophyte development. The Plant Cell 5: 1265-1275

Morison, R.A., and D.A Evans. 1988. Haploid plants from tissue culture: new plant varieties in a shorthened time frame. Biotechnology 6: 684-690

Ogawa, T., H. Fukuoka, and Y. Ohkawa. 1994. Induction of cell division of isolated pollen grains by sugar starvation in rice. Breed Sci 44: 75-77.

Segui-Simarro, J.M., P.S. Testillano, and M.C. Risueno. 2003. HSP70 and HSP90 change their expression and subcellular localization after microspore embryogenesis induction in Brassica napus L. J Struc Biol 142:379-391

Simmonds, D.H., and W.A. Keller. 1999. Significance of preprophase bands of microtubuls in the induction of microspore embryogenesis of Brassica napus. Planta 208: 383-391.

Telmer, C.A., W. Newcom, and D.H. Simmonds. 1993. Microspore development in Brassica napus and the effect of high temperature on division in vivo and in vitro. Protoplasma 172:154-165

Touraev, A., A. Ilham, O. Vicente, and E. Heberle-Bors. 1996a. Stress-induced microspore embryogenesis in tobacco: an optimized system for molecular studies. Plant Cell Rep 15: $561-565$.

Touraev, A., A. Indrianto, I. Wratscho, O. Vicente, and E. Heberle-Bors. 1996b. Efficient microspore embryogenesis in wheat (Triticum aestivum $\mathrm{L}$ ) induced by starvation at high temperatures. Sex Plant Repr 9: 209-215. 